\title{
Spatial patterns of Terrigenous Fluxes in the Tropical Atlantic since the Last Glacial Maximum
}

\author{
GEORGE H. ROWLAND ${ }^{1 *}$, LAURA F. ROBINSON ${ }^{1}$, \\ KATHARINE R. HENDRY ${ }^{1}$, HONG CHIN NG ${ }^{1}$, DAVID \\ MCGEE $^{2}$ AND JERRY F. MCMANUS ${ }^{3}$ \\ ${ }^{1}$ School of Earth Sciences, University of Bristol, Wills \\ Memorial Building, Queens Rd, Clifton, Bristol, BS8 \\ 1RJ, UK (*correspondence: gr1850@bristol.ac.uk) \\ ${ }^{2}$ Massachusetts Institute of Technology, 45 Carleton Street, \\ Building E25, Cambridge, MA 02142, USA \\ ${ }^{3}$ Lamont-Doherty Earth Observatory of Columbia University, \\ 61 Route 9W, Palisades, NY 10964, USA
}

The amount of terrigenous material moving from the continents to the ocean affects, and is affected by, climate change. Terrigenous material is delivered to the ocean by rivers, aeolian dust and the resuspension of shelf/slope material. How these fluxes change through time is related to changes in the strength and position of wind systems, precipitation belts and sea level, amongst other factors. The impact of terrigenous fluxes on ocean biology and nutrient cycles is dependent on the particular input process. The tropical Atlantic is an important region, receiving terrigenous fluxes from the world's largest riverine source (the Amazon) and the world's largest aeolian source (Saharan dust). To understand flux changes in the tropical Atlantic we compile a dataset of sedimentary ${ }^{230} \mathrm{Th}$-normalised ${ }^{232} \mathrm{Th}$ flux records since the last glacial maximum (LGM). Using our spatially and temporally resolved dataset we are able to group flux records into key regions based on magnitude and the dominant input processes. We find that sites in the western tropical Atlantic are dominated by South American inputs, even $>700 \mathrm{~km}$ from the coast. Cores at both east and west margins show a high-magnitude high-frequency variability not seen in more distal records. Having identified remote sites dominated by aeolian deposition we investigate the spatial pattern of dust fluxes in the Tropical Atlantic since the LGM. We find that spatial gradients at the southern edge of the dust plume during the LGM are similar to those during the Holocene, arguing against a large shift in the position of the intertropical convergence zone at the LGM. We also reconstruct a latitudinal difference in the LGM to lateHolocene dust flux change, with sites $>10^{\circ} \mathrm{N}$ showing less pronounced changes than those $<10^{\circ} \mathrm{N}$. These latitudinal differences imply differential changes in wind strength and/or in dust-source soil-moisture since the LGM, adding nuance to the current understanding of North African dust flux changes. 